


EDUCAÇÃO

ISSN IMPRESSO 2316-333X

ISSN ELETRÔNICO 2316-3828

DOI 10.17564/2316-3828.2016v4n3p19-30

\title{
ENTRE MILHOS E PALMATÓRIAS. MEMÓRIAS ESCOLARES SOBRE UMA INFÂNCIA CASTIGADA: VIVÊNCIAS E RESSIGNIFICAÇ̃̃ES
}

Milena Aragão ${ }^{1}$

\section{RESUMO}

O presente artigo relata e problematiza memórias e sentimentos de três professoras residentes em Aracaju-SE sobre os castigos vivenciados em sua trajetória escolar, sendo cada uma em um período histórico diferente: décadas de 1950, 1970 e 1990. Como resultado, observou-se semelhanças entre as práticas experimentadas pelas três docentes, com ênfase no uso da palmatória, ajoelhamento no milho e ficar de pé na frente da sala. Foi abordada, também, a participação das famílias nesse processo, bem como as ressignificações das entrevistadas em seus modos de pensar e agir, discutindo, para tanto, o conceito de habitus em
Anamaria Gonçalves Bueno de Freitas ${ }^{2}$

Pierre Bourdieu. Por meio das recordações docentes, foi possível não só investigar similaridades e diferenças nas práticas de castigos aplicadas no universo escolar ao longo do tempo, mas também compreender de que forma elas se apropriaram de tais vivências para compor suas práticas pedagógicas.

\section{PALAVRAS-CHAVE}

Castigos Escolares. Habitus. Memórias. 


\section{ABSTRACT}

This paper reports and discusses memories and feelings of three teachers that live in Aracaju / SE about punishments experienced in their schooler trajectory, each one in a different historical period: 1950s, 1970s and 1990s. As a result, we observed similarities between practices experienced by the three teachers, focusing on the use of the paddle, kneeling in corn and standing in front of the room. The participation of families in this process was discussed, as well as the reinterpretation of the interviewees in their ways of thinking and acting, therefore, the concept of habitus in Pierre Bourdieu was also discussed. Through memories of teachers, it was possible not only to investigate similarities and differences in practices of punishment applied in the school environment over time, but also understand how they appropriated these experiences to make their teaching practices.

\section{KEYWORDS}

Habitus. Memories. School Punishment.

\section{RESUMEN}

Este documento informa y discute los recuerdos y sentimientos de los tres profesores que viven en Aracaju / SE sobre los castigos en su trayectoria escolar, cada uno en un período histórico diferente: décadas de 1950, 1970 y 1990. Como resultado, se observó similitudes entre las prácticas experimentadas por los tres profesores, centrado en el uso de la paleta, de rodillas en el maíz y de pie en frente de la sala. Se discutió la participación de las familias en este proceso, así como la reinterpretación de los entrevistados en sus formas de pensar y de actuar, por lo tanto, también se discutió el concepto de habitus de Pierre
Bourdieu. A través de los recuerdos de los profesores, fue posible no sólo para investigar las similitudes y las diferencias en las prácticas de castigo aplicadas en el entorno de la escuela en el tiempo, sino también comprender la forma en que se apropiaron de estas experiencias para hacer sus prácticas de enseñanza.

\section{PALABRAS CLAVE}

Castigos escolares. Habitus. Recuerdos. 


\section{PALAVRAS INICIAIS}

Rememorar a vida escolar é um convite a entrar em contato com um sentimento que aperta o peito, algumas vezes faz cair lágrimas dos olhos e surgir um belo sorriso no rosto: a saudade. Saudade dos amigos, das brincadeiras, dos professores que nos acolhiam com palavras de afeto, do material escolar comprado muitas vezes com esforço dos pais, do uniforme bem cuidado, dos lanches feitos com carinho pela mãe e até do trajeto da casa para a escola, recheado de aventuras e boas conversas. Recordar é viver, como já diz o ditado popular.

Contudo, as memórias do tempo de escola não guardam apenas sorrisos. Existe uma prática culturalmente construída e utilizada pelos professores que não ficam alheios aos relatos discentes: as punições. Neste momento, os sorrisos dão lugar a uma expressão séria, como se por um momento tudo o que não foi agradável fosse revivido.

Este texto mergulha nas memórias e sentimentos de três professoras aracajuanas que relataram suas experiências de castigos como parte fundamental de suas vivências escolares no antigo primário, atual ensino fundamental menor, sendo cada uma em um período histórico diferente: décadas de 1950, 1970 e 1990.

Por meio de suas recordações, foi possível não só investigar similaridades e diferenças nas práticas de castigos aplicadas no universo escolar ao longo do tempo, mas também compreender de que forma elas se apropriaram de tais vivências para compor suas práticas pedagógicas.

\section{LEMBRANCSAS DE CASTIGOS ESCOLARES}

0 presente artigo foi composto a partir de entrevistas realizadas com três professoras residentes em Aracaju-SE, formadas em pedagogia e com experiência de trabalho nas séries iniciais do ensino funda- mental. Abaixo segue um quadro, explicitando a idade de ingresso na escola primária, bem como a cidade e o Estado onde cursaram os primeiros anos de estudo:

\begin{tabular}{|c|c|c|c|}
\hline Entrevistadas & $\begin{array}{c}\text { Ano de } \\
\text { nascimento }\end{array}$ & $\begin{array}{c}\text { Período em } \\
\text { que cursou } \\
\text { oprimário }\end{array}$ & Local \\
\hline Dora & 1946 & $\begin{array}{c}\text { Década de } \\
1950\end{array}$ & $\begin{array}{c}\text { Aracaju/ } \\
\text { SE }\end{array}$ \\
\hline Maria & 1969 & $\begin{array}{c}\text { Década de } \\
1970\end{array}$ & $\begin{array}{c}\text { Aracaju/ } \\
\text { SE }\end{array}$ \\
\hline Rosa & 1983 & $\begin{array}{c}\text { Década de } \\
1990\end{array}$ & $\begin{array}{c}\text { Aracaju/ } \\
\text { SE }\end{array}$ \\
\hline
\end{tabular}

As entrevistas foram realizadas individualmente, em hora e local previamente agendados pelas professoras. Os questionamentos foram estruturados em poucas perguntas, a fim de servir de gatilho para que cada uma expusesse com liberdade suas vivências sobre os castigos vivenciados no tempo de escola.

No quadro acima, onde são explicitadas algumas características sobre as docentes, é possível observar que há uma diferença de quase 40 anos entre a entrevistada com mais idade e a mais jovem. Todavia, no que tange aos castigos, suas memórias apresentam similaridades quanto às práticas utilizadas em sala de aula são relatadas.

A entrevistada Dora (2014) - que iniciou sua vida escolar na década de 1950 - relatou o uso de castigos corporais no seu tempo de escola: "as crianças apanhavam com palmatória e ficavam de castigo, ajoelhadas no sal ou no milho, caso não obedecessem à professora. Lembro que ela varria a sala, mas deixava o cantinho do milho ali, para todos verem!"

Tais lembranças de castigos corporais foram verbalizadas pelas outras participantes. A entrevistada 
Maria (2014) assinalou que também conviveu - na década de 1970 - com a palmatória, sendo aplicada especialmente se a criança não soubesse responder a questão formulada pela docente: "era uma vara de madeira redonda na ponta e com cinco furos! Doía mesmo! Mas o medo era tanto que a gente acabava decorando tudo". A entrevistada Rosa (2014) - que cursou o ensino fundamental na década de 1990 contou que recebeu palmatoadas por não ter levado a tarefa de casa pronta:

Eu não levei porque eu não tinha entendido e ninguém em casa sabia me ajudar, aí a professora me bateu para eu nunca mais levar nada sem fazer [... então, quando eu não sabia, eu preferia escrever qualquer coisa, mas pelo menos mostrar que eu tentei, assim ela não batia.

Os castigos físicos fizeram parte da ação docente e da vida escolar das crianças durante séculos. Seja na educação doméstica (realizada nas casas dos alunos, muito comum até os anos 1800) ou nas instituições escolares, a palmatória e o milho foram artefatos amplamente utilizados por professores para punir comportamentos considerados em desacordo com as normas. O Educador Everardo Backheuser em 1946, ao comentar sobre os castigos aplicados nas escolas brasileiras, afirmou que,

[...] tudo teria de ser contado de forma exata, como se diz, tim-tim por tim-tim, fora disso era erro, donde [havia] o aparecimento imediato da 'santa-luzia' (palmatória), da vara, do puxão de orelha, quando não do bufete. (BACKHEUSER APUD DALCIN, 2006 p. 22-23).

Nadja Bonifácio (2011), pesquisando sobre as práticas escolares do Oratório Festivo São João Bosco em Aracaju-SE, instituição destinada a recolher, instruir e educar meninas órfãs e pobres para o ensino da catequese e valores morais, identificou entre as décadas de 1914 e 1952 diversas práticas de castigos físicos, especialmente com o uso da palmatória. Outros castigos eram: reguada nas mãos, ficar de pé, puxão de orelha, e apanhar de tamanco.
Na dissertação de Josineide Santana (2011), são apresentados relatos sobre as práticas de castigos utilizadas no Orfanato de São Cristóvão e na Escola Imaculada Conceição - ambos em Sergipe - entre 1922 e 1969. Segundo as internas, os castigos mais aplicados eram por meio da palmatória e da reclusão: “Era castigo! Irmã Dileta batia mesmo na gente: palmatória, ficar trancada o dia todo no quarto. Fazia as refeições, mas ficava trancada. Elas batiam" (APUD SANTANA, 2011, p. 99).

No depoimento acima, é possível observar o uso de outros tipos de castigos além dos castigos físicos, como o isolamento em outro cômodo. Nas memórias das entrevistas, também são relatados castigos que não atingiam o corpo. A entrevistada Dora (2014), que fez o primário na década de 1950, afirmou que alguns alunos ficavam de pé na frente da turma, com a face voltada para o quadro de giz, caso conversassem durante a aula.

A participante Maria (2014) relatou ter presenciado o mesmo castigo visto pela Dora (2014), afirmando ainda ser comum - além deste -- a perda do recreio. Depoimento corroborado pela Rosa (2014) que, na década de 1990, afirmou ter visto a professora deixar alunos de pé em um canto da sala, ou sem recreio, ou ainda após o horário de aula.

Os castigos ora relatados, que não são direcionados ao físico, são chamados de castigos morais, pois tem o objetivo de incitar a vergonha e o embaraço nos alunos. De acordo com Veiga (2009)

O sentimento de vergonha expressa um medo de degra-
dação social, uma experiência de inferioridade e uma im-
potência total ante a ameaça do outro, não se manifesta
por gestos violentos e é sempre velado. Já o embaraço
indica para uma situação de perturbação quando ocorre
infração de alguma regra. (VEIGA, 2009, p. 67-68).

Rosa (2014) relembra ter se sentido, bastante envergonhada, quando a professora aplicou o castigo de ficar em pé na frente de toda a classe, junto ao quadro: 
Eu fiquei de castigo durante toda a aula porque eu não sabia responder a uma pergunta. Eu nunca esqueci disso, até hoje eu me vejo com a farda vermelha e ela sentada de trás da mesa dizendo: "você vai ficar aí". E eu morta de vergonha porque todos os meus colegas sabiam fazer e eu fui a única que não soube e todo mundo ficava me olhando.

Outra ação docente considerada por elas como castigo foram as humilhações por meio de palavras. Dora (2014) afirmou que, além das palmatoadas e do milho, as professoras "xingavam os alunos, diziam: saia daqui, cale a boca menino! Fique calado porque você está falando, fique calado e no seu lugar, sua peste!". Dora (2014) afirmou, ainda, ser comum ouvir professoras chamando as crianças de praga, peste ou diabo.

Maria (2014) e Rosa (2014) também relataram em suas experiências escolares nas décadas de 1970 e 1990 respectivamente, ter sido comum professoras gritarem com alunos de forma a envergonhá-los frente ao grupo. Alegaram que as palavras mais comuns eram: burro, imbecil, peste, praga e diabo. Quando questionadas sobre o sentimento envolvido ao presenciarem ou passarem por tais situações, todas foram categóricas: vergonha e medo. "Os professores faziam a gente passar vergonha”, comentou Rosa (2014).

A punição física foi dividindo (e também perdendo) espaço com as punições morais a partir do século XIX, quando a questão dos castigos apareceu na primeira legislação de ensino, instituída em 15 de outubro de 1827, referenciada no art.15, o qual designa seu uso pelo Método de Ensino Mútuo ou Lancasteriano (BASTOS; FARIA FILHO, 1999), que refutava os castigos físicos e indicava os de cunho moral como forma de punir e educar crianças.

Assim, o século XIX foi palco de esforços do governo (por meio de legislações) e de educadores (por meio de textos em jornais e revistas) no sentido de divulgar formas de castigo sem o uso do avilte físico (VASCONCELOS; SOARES, 2004; CASTRO, 2010). No cotidiano, por outro lado, a palmatória continuava a ser utilizada nas salas de aula, nesse e no século posterior, como observado nos relatos das entrevistadas.

Neste contexto de castigos escolares, a família não ficava alheia. Nos depoimentos colhidos foi possível perceber que os pais das entrevistadas condenavam o uso das palmatórias e do milho, contudo diziam que não poderiam interferir na decisão docente: "minha mãe não se metia, porque ela dizia que quem manda na sala de aula era a professora e quem manda em casa eram os pais", afirmou Dora (2014).

Maria (2014) também alegou que seus pais consideravam os castigos físicos inadequados, mas preferiam não confrontar a professora, já que esta era a autoridade em classe. Rosa (2014) relatou que seus pais foram chamados em sala de aula porque seu irmão mais velho havia revidado uma palmatoada que a professora proferiu em sua mão: "meu irmão jogou a cadeira nela, ele disse que só quem batia nele eram meus pais!" Contudo, os pais de Rosa (2014), assim como o das outras entrevistadas, não intervinham nas ações docentes pela crença na autoridade destes: "meus pais achavam errado, mas a professora era boa, ensinava bem, então eles deixavam acontecer".

Tais depoimentos apontam para algumas reflexões. Primeiramente é possível pensar sobre a legitimidade docente, ou seja, as famílias reconheciam a professora como detentora de um saber e de um poder, de modo que não se sentiam aptas a intrometerem-se na forma como a educadora ensinava e corrigia seus filhos: "ela era a professora, ela sabia o que estava fazendo, era para o nosso bem, assim como nossa mãe fazia", comentou Maria (2014), corroborada pelos depoimentos das outras entrevistadas.

A segunda reflexão diz respeito à relação entre o papel materno/paterno e o docente, conforme assinalado no depoimento supracitado. Souza (2003) afirmou - em suas investigações sobre a Revista de Ensino de Minas Gerais nas primeiras décadas do século XX - que o discurso que interpunha a docência 
à paternidade/maternidade era fortemente difundido, conjugado à ideia de racionalização dos sentimentos:

[...] essencial que fossem [os castigos] "racionalizados", ou seja, aplicados com cautela, sem o domínio das emoções, e tomando-se diversos cuidados. Um desses cuidados estava relacionado à aproximação do mestre com a figura familiar. Acreditava-se que o castigo aplicado pela família vinha acompanhado de um sentimento de amor. [...] 0 professor, após a aplicação de diversas tentativas disciplinares sem que estas atingissem os feitos almejados, poderia fazer uso das punições, mas era preciso fazê-lo de forma que não despertasse a ira de seus alunos, agindo como se fosse um pai, ou seja, castigando por amor e não por vingança. (SOUZA, 2003, p. 609).

Se o pai tinha sua ação socialmente legitimada no que concerne ao castigo físico, e sendo o professor muitas vezes comparado a um pai, ele também teria o poder de aplicar castigos. É como recordar a feminização do magistério, na qual mulheres-professoras primárias tinham a escola como a extensão do lar, não só para o cuidado e educação, mas também para as práticas punitivas. A representação da escola como a extensão do lar permaneceria, então, quando se tratava dos castigos? Pois bem, as crianças e jovens tinham um pai em casa e um "pai" na escola, nesse sentido, a escola e a família muitas vezes eram cúmplices na educação da criança.

Mesmo que a escola não tenha sido norteada pelos mesmos princípios educativos que a família (relativo a métodos de ensino, tempos e espaços), com relação aos castigos suas práticas eram bastante similares: "eu até nem estranhava a palmatória, por que em casa, quando o bicho pegava, a palmatória cantava!" afirmou Dora (2014); "Palmatória tinha lá em casa, mas era para assustar, eu mesma nunca apanhei, mas se eu saísse da linha eu sabia que ia levar!" Contou Maria (2014). "Meu pai apanhou de palmatória do meu avô, mas ele não batia não, ele usava cinta mesmo, mas sempre ameaçava, dizendo que palmatória era pior! Também tinha o castigo de ficar num canto, trancados no quarto", relatou Rosa (2014).
Possivelmente, pelo fato de o castigo utilizado em casa ser similar ao usado na escola, os pais não estranhava esta prática, especialmente se eles confiavam no trabalho docente, ou seja, se eles viam que seus filhos estavam aprendendo.

Os relatos ora apresentados abarcam três tempos históricos: décadas de 1950, 1970 e 1990. As permanências nos discursos podem levar à interpretação de não ter havido mudanças, todavia, a tolerância das famílias para a prática dos castigos em sala de aula foi sendo gradativamente reduzida ao longo dos anos, de modo que foi explicitada na fala da Rosa (2014) - a mais jovem das participantes - que os pais de outros alunos queixavam-se constantemente da professora, alegando que os castigos físicos não eram formas adequadas para ensinar crianças.

Assim, a professora em questão "batia somente naqueles que os pais permitiam", manifestou Rosa (2014), afirmando, ainda, que os castigos físicos cessaram em decorrência do Estatuto da Criança e do Adolescente (Lei n 8.069 de 13 de julho de 1990), pois a professora temia ser denunciada.

Os depoimentos sobre os castigos vivenciados na escola, apontados tanto pelas entrevistadas, como os citados por outros pesquisadores são lembranças individuais de suas vivências no universo escolar, mas são também reminiscências coletivas, memórias de um grupo social.

Para Halbwachs (2006) mesmo que aparentemente particular, a memória remete a um grupo; o indivíduo carrega em si a lembrança, mas está sempre interagindo na sociedade, já que "nossas lembranças permanecem coletivas e nos são lembradas por outros, ainda que se trate de eventos em que somente nós estivemos envolvidos e objetos que somente nós vimos" (HALBWACHS, 2006, p. 30).

Assim, a memória individual está enraizada em diferentes contextos, com a presença de diferentes parti- 
cipantes, e isso permite que haja uma transposição da memória individual para se converter num conjunto de acontecimentos partilhados por um grupo, passando de uma memória individual para uma memória coletiva.

\section{RESSIGNIFICANDO AS EXPERIÊNCIAS VIVIDAS: PORQUE ELAS CASTIGAVAM?}

No processo de entrevista, ao relembrar suas vivências na escola, as professoras relataram não só sobre os tipos de castigos vivenciados, mas também os motivos que acreditavam levar as professoras a utilizar castigos tão dolorosos para punir comportamentos, como a palmatória e o ajoelhamento no milho, memória bastante presente nas três participantes.

Dora (2014) alegou que "na época de criança eu não sabia por que, eu a via meio como mãe, que deve castigar o filho, mas eu ficava com raiva, com muita raiva dela e com medo também". Contudo, com o amadurecimento, ela percebeu que as professoras batiam nos alunos por manifestarem o que vivenciaram na sua própria infância: "eu acho que essas pessoas fazem isso porque passam aquilo que viveram. Uma das professoras disse: meu pai me bateu para eu aprender, porque não posso bater nessas pragas?”

Maria (2014) afirmou que "na época era ruim, eu ficava com medo e achava que era normal, mas hoje eu vejo que tudo passa pela forma como você vê o mundo, pela experiência que você tem, talvez já tenha passado por isso, já tenha apanhado”. Diz, ainda:

\footnotetext{
Na minha vida assim, no primário, de me lembrar de castigo...tinha essa freira que tinha uma varinha que qualquer coisa, escreveu não leu, ela batia, mas já era como uma coisa própria dela, ela era ríspida mas era o jeito dela, como se ela não conseguisse ser de outra forma, como se você não conhece você fica horrorizado, mas quando conhece acha até engraçado, como se fosse legítimo para ela, mas dá uma frustração, uma coisa assim muito ruim, de impotência, de você ver, e que aquilo pode acontecer com você né. (MARIA, 2014).
}

Rosa (2014), concordando com Maria (2014) e Dora (2014), profere o seguinte depoimento:

\begin{abstract}
Eu não gostava, não tem como gostar, me dava vergonha e eu não pensava nos motivos dela, eu só sentava e tentava obedecer [...] Mas vendo por hoje, eu acho que os professores até tem amor aos alunos, mas como estudaram no tempo antigo, então foi isso que eles aprenderam, porque antes os alunos não tinham voz ativa, só os professores mandavam, então se os alunos desobedeciam, eles batiam, eu acho que esses professores tem até amor, mas foi a maneira que eles aprenderam, como eles viveram no passado, eles faziam isso. Muitos professores são assim hoje, vai no interior e fale com professores. São aqueles que não pensam sobre o que fazem que só reproduzem o tempo antigo.
\end{abstract}

A entrevistada Rosa (2014) estudou na década de 1990, a Maria (2014), na década e 1970 e a Dora (2014) na década de 1950. São 20 anos de diferença entre as entrevistada e todas alegam que as práticas de castigos são fruto das vivências docentes "do tempo antigo", onde as professoras - quando alunas - experimentaram em seus corpos as varadas, palmatoadas e milho, levando consigo, para suas atividades profissionais, as "verdades" construídas na infância sobre a maneira adequada de punir crianças.

Em outras palavras, fala-se do habitus, um conceito proposto por Pierre Bourdieu para pensar as práticas cotidianas.

De acordo Bourdieu (1998), habitus é a internalização de traços culturais; um processo de inculcação de valores, condutas e comportamentos que o sujeito incorpora ao longo da vida sem que tenha consciência. Ele está presente quando o sujeito age automaticamente. "É uma espécie de senso prático do que se deve fazer numa determinada situação" (BOURDIEU, 1998, p. 42). "É um corpo socializado, que incorporou as estruturas imanentes de um mundo ou de um campo e que estrutura tanto a percepção desse mundo como a ação nesse mundo" (BOURDIEU, 1998, p. 144). 
Ao transportar para o universo dos castigos, é possível pensar que a escolha do tipo de castigo a ser aplicado depende de uma série de crenças e valores culturais e sociais que foram assimilados ao longo dos anos sobre como punir crianças, o qual é vivenciado e posto em prática em situações específicas, de acordo com os estímulos do espaço onde transita, neste caso, o universo escolar.

Assim, ao refletirem na vida adulta sobre o que vivenciaram na infância, as professoras conseguiram ressignificar suas experiências, ou seja, dar um novo sentido àquilo que já estava formatado em seus sistemas de crenças e valores. Quando crianças elas acreditaram que fazia parte do papel docente, entretanto, na vida adulta, após encontros com outras formas de pensar e agir, refletiram sobre a característica cultural dos castigos, o que possibilitou mudanças.

\section{CASTIGOS: RESSIGNIFICANDO PRÁTICAS}

$\mathrm{Na}$ opinião das entrevistadas, os castigos seguem uma lógica cultural que diz que a criança precisa ser punida para reconhecer seu erro. Neste sentido, mesmo que as recordações das depoentes tenham ocorrido em datas diferentes, havia um contexto cultural comum, onde os castigos, especialmente em sua forma física, eram utilizados como meio de punir um comportamento considerado incorreto.

Cipriano Luckesi (1990) assevera que a prática do castigo parte da ideia de que o aluno erra porque não sabe, não sabe por que não prestou atenção à explicação do professor, justificando a punição. A responsabilidade pelo não aprendizado recai sobre o desinteresse do aluno e, para tanto, entende-se que o castigo corrija a situação.

Isso conduz à percepção de que o entendimento e a prática do castigo decorrem de uma visão culposa dos atos humanos. Ou seja, a culpa está na raiz do castigo. No caso da escola, este senso caminha pela seguinte seqüência: um aluno manifesta uma con- duta não-aprendida e, por isso, segundo o senso comum, é culpado; como tal deve ser castigado de alguma forma, a fim de que adquira e direcione seus atos na perspectiva da conduta considerada adequada. Nesta perspectiva, o erro é sempre fonte de condenação e castigo, porque decorre de uma culpa e esta, segundo os padrões correntes de entendimento, deve ser reparada. Esta é uma compreensão e uma forma de agir que configuram nosso modo cotidiano de ser. (LUCKESI, 1990, p. 135).

Maria (2014) corrobora a citação anterior ao alegar que os castigos que vivenciou ou presenciou foram fruto da responsabilidade do aluno: "eu acho que eu fui castigada porque fiz algo de errado, porque não respeitei ou não fiz o exercício". Esta frase resume o depoimento das outras duas participantes. As três alegam que os castigos servem para punir um comportamento inadequado, mas que seriam desnecessários caso a professora organizasse uma aula que "atraísse a atenção do aluno”, como apontou Rosa (2014).

A ideia de uma aula organizada no sentido de "atrair a atenção do aluno" foi sistematizada por John Dewey (1859-1952), filósofo norteamericano e pensador da educação. Dewey (2007) engendrou uma escola capaz de preparar para a vida, ou seja, propor condições de tornar o homem possuidor de capacidade de sustentação do processo contínuo de educação, no qual a liberdade, o conhecimento e a moral não estivessem dissociados.

A escola defendida por Dewey (2007) deveria ser um espaço no qual os alunos pudessem desenvolver livremente o seu potencial individual, onde prevalecesse a centralidade da criança no processo educativo, a atenção ao potencial do aluno e a elaboração de aulas focadas nas experiências práticas, refutando verbalismos ou memorizações. A relação professor-aluno também foi questionada, tendo em vista o autor negar o autoritarismo docente, em especial com uso de ameaças e castigos físicos. 0 papel do professor estava em identificar quais os interesses e competências dos alunos e oferecer oportunidade para que fossem desenvolvidas, estimulando-os a aprender com prazer. 
Os pensamentos sobre educação de John Dewey foram amplamente disseminados em solo brasileiro a partir da década de 1930, apoiado no movimento conhecido por “Escola Nova”. Vidal (2000, p. 497) assinalou que,

A "Escola Nova" produziu enunciados que, desenhando alterações no modelo escolar, desqualificavam aspectos da forma e cultura em voga nas escolas aglutinadas em torno do termo "tradicional". Era pela diferença entre as práticas e saberes escolares anteriores que se construía a representação do "novo" nessa formação discursiva.

Nesse processo de repensar ideias e práticas "antigas”, os castigos entraram em cena, especialmente em sua representação física, sendo duramente criticados por seguidores do escolanovismo que advogavam pelo respeito aos direitos individuais da criança. Assim, era lugar comum afirmar que as punições deveriam ser eliminadas da escola ou, para os mais céticos, minimizada, sendo necessária para isso uma única condição: a qualificação dos docentes segundo os novos modelos pedagógicos. Bastava, dizia-se, seguir os interesses da criança, identificados a partir dos estudos sobre o desenvolvimento psicológico infantil, respeitando seu potencial e suas limitações e promover um ensino ativo para se obter a disciplina sem a necessidade de punições (SOUZA, 2003).

Destarte, as entrevistadas verbalizaram que, apesar de compreender as ações de suas professoras, afirmaram que suas práticas diferiam das que vivenciaram. Alegaram preferir utilizar estratégias para manter a atenção dos alunos, as quais aprenderam no curso de formação e lapidaram na prática cotidiana, tais como: "ouvir sobre cada um, entendendo suas histórias de vida” (DORA, 2014); "estabelecer rotinas, [...] ter uma postura alegre" (ROSA, 2014); "elogiar muito" (MARIA, 2014); "construir a aula partindo do interesse dos alunos" (DORA, 2014; MARIA, 2014; ROSA, 2014); "eleger os mais agitados como ajudantes" (ROSA, 2014); "contar histórias" (DORA, 2014; MARIA, 2014) e "não humilhar ou gritar com as crianças" (DORA, 2014; MARIA, 2014; ROSA, 2014)
Afirmaram, ainda, que ao escolherem a docência, prometeram a si mesmas não reproduzirem os castigos vivenciados, tendo em vista as experiências desagradáveis que tiveram. Todavia, asseguraram que utilizam castigos "somente em último caso, quando a criança realmente não se comporta", conforme alegou Rosa (2014), que foi aluna das primeiras séries do ensino fundamental na década de 1990 e atualmente é professora de crianças do segundo e terceiro ano, também do ensino fundamental:

\begin{abstract}
Eu uso a cadeira do pensamento quando eles estão agitados, ou retiro algo que gostam, como uma brincadeira, caso descumpram o combinado; ou acabo dando um bronca e colocando de pé, como último recurso, mas realmente esse não é meu foco, eu procuro mesmo conversar e entender o motivo que ela o aluno a fazer aquilo.
\end{abstract}

No depoimento acima, Rosa (2014) afirmou que utiliza o mesmo artifício que vivenciou em seu tempo de escola: ficar de pé. Todavia, assevera ser somente como "último recurso", ou seja, única possibilidade encontrada para fazer cessar o conflito, como se - ao não saber o que fazer - recorresse ao que lhe é íntimo, ao que vivenciou ao longo da vida. Nesse sentido, retomamos um termo já evidenciado ao longo do texto: o habitus. Rosa (2014), ao utilizar um dos tipos castigos vivenciados em sua história escolar, reproduziu as estruturas adquiridas pela experiência, tendo em vista ainda estar incorporada em sua forma de ser e pensar, mesmo que ela - conscientemente - o refute: "Não gostei de ficar de pé na aula, me deu vergonha".

Entretanto, Bourdieu (1998, p. 106) assegura que o habitus não é estático, "é também adaptação, ele realiza sem cessar um ajustamento ao mundo", tendo em vista as pressões das novas experiências vividas pelos atores sociais. Assim, a utilização do castigo de "ficar de pé" como último recurso, sinaliza para as mudanças que Rosa (2014), mas também as outras entrevistadas conseguiram edificar em suas práticas. Tal como no item anterior, as entrevistadas atribuíram um novo significado aos acontecimentos por meio da mudança de visão de mundo. 
Observa-se, por meio dos relatos, que as vivências infantis com os castigos ajudaram a compor a "personagem" professora, evidenciando que a docência não se constrói somente nos cursos de formação, com técnicas e métodos de ensino, mas também a partir das experiências de vida, refletindo sobre a cultura na qual estão imersas. Conforme Bourdieu (1998), os mecanismos de manutenção das práticas são passíveis de questionamento, bem como suas próprias práticas, o que pode ser o início de sua transformação.

\section{PALAVRAS FINAIS}

No presente texto, uma parte da cultura escolar foi revisitada por meio da memória da Dora, da Maria e da Rosa, três professoras que viveram em diferentes períodos históricos, mas que compartilharam uma mesma lembrança: os castigos aplicados em sua vida escolar: palmatoadas, ajoelhamento no milho, ficar de pé da sala, gritos, humilhações. Leis e discursos, mesmo buscando coibir os abusos no uso dos castigos, em especial na forma física, não foram suficientes para inibir tais práticas, tendo em vista as similaridades nos depoimentos.

Logo, pensar em castigos escolares leva-nos a refletir sobre a cultura, a história, a sociedade. Nosso sentido sobre o que constitui uma forma de castigo consciente, tolerável e civilizada está determinado, em grande medida, pelos padrões culturais, assim como são os sentidos sobre o que é intolerável e desumano. Desta forma, a cultura delimita os contornos e os limites externos dos castigos, suas formas distintivas, hierárquicas e categorias, bem como proporcionam os marcos intelectuais (científicos, religiosos ou de senso comum), por meio dos quais entendemos as motivações que embasam as ações.

Problematizar os castigos escolares remete olhar para o cotidiano da escola, abrir as salas de aula, percorrer refeitórios e corredores, além de considerar a docência e sua articulação com o ambiente doméstico.
Estimula também, a sair da escola e olhar para a sociedade onde esta escola faz parte, para a cultura que constrói e legitima os castigos em diferentes tempos históricos, para as relações de poder e geracionais, para o que os sustenta, suas rupturas e descolamentos; concebendo os castigos como um fenômeno sociocultural que marcam - como tatuagem - a infância, a escolarização e as ações do sujeito. É fundamental ponderar essas e outras questões relevantes que se mostram como o "em torno" e, às vezes, o centro de um debate profícuo para a História da Educação brasileira.

\section{REFERÊNCIAS}

BASTOS, Maria Helena; FARIA FILHO, Luciano Mendes (Org.). A escola elementar no século XIX: o método monitorial/mútuo. Passo Fundo: Universitária, 1999.

BONIFÁCIO, Nadja Santos. Acolher, evangelizar e educar. Contribuição do Oratório Festivo São João Bosco para educação feminina em Aracaju (19141952). 2011. Dissertação (Mestrado) - Programa de Pós Graduação em Educação da Universidade Federal de Sergipe, São Cristóvão: UFS, 2011.

\section{BOURDIEU, Pierre. Escritos de educação.}

NOGUEIRA, Maria Alice; CATANI, Afrânio (Org.).

Petrópolis-RJ: Vozes, 1998.

\section{CASTRO, César Augusto. Infância e trabalho}

no Maranhão Provincial: uma história da Casa dos Educandos Artífices (1841 - 1889). São Luiz: EDUFMA , 2010.

DALCIN, Talita Banck. "Palmatoando" as fontes: os usos dos castigos físicos em nome da disciplinarização e da ordem nas escolas paranaenses da segunda metade do século XIX. In: OLIVEIRA, Marcus Aurélio Taborda de (Org.).

Educação do corpo na escola brasileira. CampinasSP: Autores Associados, 2006. p. 71-93. 
DEWEY, John. Democracia e educação: capítulos essenciais. São Paulo: Ática, 2007.

HALBWACHS, M. A memória coletiva. Tradução Beatriz Sidou. São Paulo: Centauro, 2006.

LUCKESI, Cipriano Carlos. Prática Escolar: do Erro Como Fonte de Castigo ao Erro Como Fonte de Virtude In: FDE. (Org.). Caderno Idéias, v. 8. São Paulo: FDE - Fundação para o Desenvolvimento da Educação, 1990. p.133-140.

SANTANA, Josineide Siqueria de. Entre bordados, cadernos e orações: A educação a educação de meninas e as práticas educativas no orfanato de São Cristóvão e na Escola da Imaculada da Conceição (1922-1969). 2011. Dissertação (Mestrado) - Programa de Pós Graduação em Educação da Universidade Federal de Sergipe, São Cristóvão: UFS, 2011.

SOARES, Marcilaine Inácio; VIANA, Fabiana da Silva. $A$ instrução elementar e os castigos escolares em Minas Gerais no século XIX. III Congresso Brasileiro de História da Educação. Anais... Curitiba: Pontifícia Universidade Católica do Paraná, 2004
SOUZA, Rita de Cássia. Punições e disciplina: introdução ao estudo da cultura escolar. II Congresso de Pesquisa e Ensino em História da Educação em Minas Gerais, Anais... Uberlândia, 2003. Disponível em: <http://www.faced.ufu.br/nephe/images/arqind-nome/eixo7/completos/punicoes-disciplina.pdf>. Acesso em: 8 jun. 2014

\section{VASCONCELOS, Maria Celi Chaves. A casa e seus} mestres: a educação no Brasil dos Oitocentos. Rio de Janeiro: Gryphus, 2005.

VEIGA, Cynthia Greive. Elaboração de hábitos civilizados na com stituição das relações entre professores e alunos (1827-1927). Revista Brasileira de História da Educação, n.21, set.-dez. 2009. 218p. Disponível em: <http://www.sbhe.org.br/novo/rbhe/ RBHE21.pdf>. Acesso em: 17 jun, 2014.

VIDAL, Diana Gonçalves. Escola nova e o processo educativo (1920-1930). In: LOPES, Eliane Teixeira; FARIA FILHO, Luciano M.; VEIGA, Cynthia G. (Org.). 500 anos de educação no Brasil. V.1, 2.ed. Belo Horizonte: Autêntica, 2000. p.497-517. 
Recebido em: 24 de junho de 2014

Avaliado em: 28 de junho de 2014

Aceito em: 20 de abril de 2015
1. Mestre em Educação. Doutoranda em Educação pela Universidade Federa de Sergipe. Bolsista FAPITEC/SE. E-mail: mi.aragao@yahoo.com.br

2. Professora Doutora do Departamento de Educação da Universidade Federal de Sergipe e do PPGED/UFS. Orientadora de Mestrado e Doutorado. E-mail: anagbueno@uol.com.br 